\title{
IMPACT OF GALLERIA MELLONELLA AND ACHROIA GRISELLA (WAX MOTH) TO APICULTURE
}

\section{VINITA PAULINA TOPNO \& LOVLEEN}

Department of Zoology, School of Bioengineering and Biosciences, Lovely Professional University, Phagwara, Punjab, India \begin{abstract}
The honeybee is known since ancient time as an important insect in the world that produces propolis, pollen, royal jelly, honey and bee wax. The honey bee hive gets infected by the pest such as the greater and the lesser wax moth. Wax moths are troublesome pests that cause considerable financial loss to the beekeeping industry every year all over the world. Wax moths are more active in high temperature, that are destructive and can quickly destroy the comb by feeding on the hive. The prevalence of wax moth is high in warmer area. The damage caused by the wax moth is high in tropical and subtropical region. The high level of infestation reduces the yield of the honey which lead to heavy economic loss to beekeepers. This review gives an overview of the infestation rate of wax moth and their impact on the honey bee population, apiaries and honey products.
\end{abstract}

KEYWORDS: Beekeeping Industry, Financial Loss, Honeybee Population, Infestation \& Wax Moth

Received: May 09, 2021; Accepted: May 29, 2021; Published: Jun 15, 2021; Paper Id.: IJZRDEC20211

\section{INTRODUCTION}

Bee wax is one of the useful product of apiculture has numerous use in beekeeping as well as other industries such as pharmaceutical and cosmetic industries (Hanumanthaswamy and Rajagopal, 2017). Wax moth infestation in honey bee colony cause economically great loss to beekeeping industry worldwide annually. The wax moth alone can cause heavy economic loss (60-70\%) to beekeeping industry by damaging honey combs, colony dwindle and absconding (Ambaw et al., 2020; Hanumanthaswamy and Rajagopal., 2017). Poor management in beekeeping weakens the colonies by which pest easily infest the colony. The larvae of wax moth feed on the bee hive and damage the bee hive severely (Elbehery et al., 2016). These are of two species of wax moth namely Galleria mellonnella (greater wax moth) and Achroing grisella (lesser wax moth). These moths cause damage maximum in tropical and subtropical region and is responsible for decline in honey bee population (Negi et al., 2019). Thus, there is a need to control wax moth by various mechanical, physical, biological and chemical control methods.

\section{TYPES OF WAX MOTH}

Wax moth are categorized as greater wax moth (Galleria mellonella) and lesser wax moth (Achroia grisella)

\subsection{Greater Wax Moth (Galleria mellonella)}

Wax moths are about 20mm in length but their size depends on the supply of food and temperature during developing period of larval and pupal stages (Ellis et al., 2013). Male greater wax moths are slightly smaller in size and light in colour as compare female wax moth (Ellis et al., 2013; Desai et al., 2019; Kumar et al., 2018; Kwadha et al.,2017). Female lay cluster of 50-150 eggs on the comb or in the small cracks present in the hive (Kwadha et al., 2017; Burges, 1978; Wojda et al.,2020). Wax moth eggs are spherical, pinkish to white (Kwadha et al.,2017; Desai et al., 2019) with 
average length and width of about $0.47 \mathrm{~mm}$ and $0.39 \mathrm{~mm}$ respectively (Kwadha et al., 2017). Eggs hatches within 3 to 5 days at the temperature of about $29-35^{\circ} \mathrm{C}$ (Vijayakumar et al., 2019; Kumar et al., 2018). At the temperature of $18^{0} \mathrm{C}$, the hatching extends to about 30 days after the laid of eggs (Ellis et al., 2013; Kumar et al., 2018). After hatching, the larvae are small but are very active, begin tunnel through comb and lining their tunnels with silky web as they go (Ellis et al., 2013). Larvae are about $25 \mathrm{~mm}$ long and creamy white in color but turn to grey later on (Kwadha et al., 2017; Kumar et al., 2018). There are seven larval instars (Vijayakumar et al., 2019). Wax moth larvae are active in a warm condition and highly destroy the comb (Desai et al., 2019). Inside the cocoon, the newly formed pupa is white and later on further development changes to brown (Swamy, 2008). The size of greater wax moth pupae ranges from $5 \mathrm{~mm}$ to $7 \mathrm{~mm}$ in diameter and $12-20 \mathrm{~mm}$ in length (Ellis et al., 2013). The pupation last for about 8 days at the temperature of $28^{\circ} \mathrm{C}$ and to $\sim 50$ days at $2.5-28^{0} \mathrm{C}$ (Kumar et al., 2018; Wojda et al., 2020). Adult male and female moths mate and the cycle repeats again. The life cycle of wax moth is discussed below in fig. 1 .

\subsection{Lesser Wax Moth (Achroia grisella)}

The female adult lesser wax moths are about $13 \mathrm{~mm}$ long and male are $10 \mathrm{~mm}$ in length, and silver-grey to buff in colour (Ellis et al., 2013). The lesser wax moth larvae are smaller in size as compare greater wax moth as the name implies. Lesser wax moth larvae are 15-20mm in length (Gulati and Kaushik, 2004; Tej et al., 2017). Lesser wax moth also feeds on same food as the greater wax moth do (Tej et al., 2017). The larvae of lesser wax moth are usually live solitary and on the other hand the larvae of the greater wax moth congregate in large number (Gulati and Kaushik, 2004; Ellis et al., 2013).

\section{IMPACT OF WAX MOTH ON APICULTURE}

Wax moth causes no direct destruction to honey bees at any living stage but they eat wax and other associated material of the comb such as pollen, wax, propolis dead bees (Swamy, 2008). It causes damage to honey bee colonies which lead to heavy economic loss to bee industry. The larvae of the wax moth burrows through combs eating wax, pollen and honey and damaging the bees in the cells through which it tunnels (Hosamani et al., 2017). The pest harms the honeybee population by destroying the brood comb (Kapahi and Lovleen 2019). These pests make silky web like 'spider web' in the comb. Usually wax moth infests the empty or weak comb that are previously used by bees. Weak combs are more susceptible to wax moth as compare to strong colony that cover all the combs in the hive (Kapahi and Lovleen, 2019).

\subsection{International Status}

The greater wax moth is responsible for heavy economic loss (60-70\%) yearly all over the world (Hanumanthaswamy and Rajagopal, 2017). The profit estimated in 1973 and 1978 were approximately 3.9\% and 5.1\% respectively and losses estimated approximately $\$ 3$ and $\$ 4$ million in the respective year (Kwadha et al., 2017). In the year 1997, in the states of Florida and Texas, loss recorded were approximately $\$ 5$ and $\$ 1.5$ respectively (Kwadha et al., 2017). In Iran, the economic losses due to wax moth infestation estimated to 38\% (Kwadha et al., 2017). The economic losses reached to $40 \%$ in Egypt (Adly and Marzouk, 2019). The prevelance of wax moth in modern hive of Kafta Humera found to be $24.7 \%$ (Kebede et al., 2015). The survey by (Ambaw et al., 2020) show the prevalence of wax moth in three zones of Oromia region; South West Shoa and West and East Shoa Zones ranges from 22.85\% -26.66\%. Further, it indicated that the prevalence of wax moth infected honey bee colonies absconded about $56 \%-75 \%$ and the remaining dwindle. 


\subsection{National Status}

The percentage of 16-19 percent infestation of wax moth recorded in northern India (Bhatnagar et al., 2020; Lalita et al., 2018) and peak abundance of wax moth recorded in the month of August (Sohail et al., 2017). In 2016 the percentage of greater wax moth infestation in different parts of Karnataka such as Bengaluru rural (38.71\%), Chitradurga (52.63\%), Devanagere (45.5\%), Coorg (26.53\%), Shivamogga (42.8\%), Uttara Kannada (26.4\%), Dakshina Kannada (27.78 \%) and Chikkaballapur (70 \%) (Vijayakumar et al., 2019).

\section{DAMAGE CAUSED BY WAX MOTH}

\subsection{Beehive and Apiary Products}

In a weak colony, bees cannot effectively protect their hive against the wax moth (Bhatnagar et al., 2020). The bee colony become weak due to queenlessness, starvation, worker bees' mortality due to disease or toxic pesticides (Komala and Devina, 2020). The adult female wax moth enters the hive and lay eggs. The eggs hatch and soon, the unprotected or unused hive get infested with the larvae (Ellis et al., 2013). In a strong bee hive, wax moths are numerically less and they do very little damage to the bee hive, moreover, mostly in the strong colony wax moth are removed by bees (Goodman, 2015). Wax moth larvae destroy the comb by feeding on pollen, cast larval skin, wax comb and honey present in the hive (Ellis et al., 2013; Bhatnagar et al., 2020). The hive with pollens containing eggs, these eggs hatches any time after packing making unsuitable for human consumption. Uncleaned or unrefined comb contain tiny eggs which are unsuitable for sale and consumption as eggs can hatch any time and the larvae begin tunneling.

\subsection{Galleriasis}

The wax moth tunnels at the base of the cell in the hive due to which newly formed bees unable to emerge from their cells after the removal of the capping as the bees are trapped by silken thread spun by greater wax moth larvae (Lalita et al., 2018; Ellis et al., 2013). Eventually the trapped bees die inside cells and are later removed by the bees (Goodman, 2015).

\subsection{Bald Brood}

When wax moth partly removes the cell caps in the hive, the developing honey bee pupae are exposed. The worker honey bee exposes the heads of the pupae which continue to develop normally by chewing the remainder of the capping (Ellis et al., 2013). When the wax moth tunnel through the brood comb, their excreta can affect the final moult of honey bee pupae (Ellis et al., 2013). The bee pupae may get deformity in their legs or wings (Goodman, 2015).

\subsection{Stored Comb}

Damage caused by the wax moth depends on the extent of infestation and the time of infestation first began. Wax moth causes heavy damage to apiaries if the colony is weak. In heavy infestation, the wax moth destroys the comb completely as the comb completely filled with silk web (Vijayakumar et al., 2019; Tsegaye et al, 2014). The wax moth larvae also destroy the frames and hive by chewing the wood to make cavities for the cocoons (Ellis et al., 2013; Tsegaye et al., 2014). Wax moth prefers mostly dark brood comb containing pollens, honey bee and wax (Tsegaye et al., 2014).

\section{CONCLUSIONS}

The greater and lesser wax are the global challenge to bee health and beekeeping industry. Besides, it damages wax combs by larval feeding and destroy wooden parts and frames in the hive. The wax moth makes silken tunnels on or just below the surface of capping. The honey oozes out from the holes made by wax moth while tunneling or feeding. Moreover, it also 
reduces the yield of packed honey as the egg hatches, the larvae grow inside the honey that start webbing inside the honey make the honey unfit for human consumption. Usually, uncleaned honey contains wax moth eggs. These eggs hatch inside the honey, the larvae develop and grow inside the honey that start webbing. The webbing and debris make the honey unattractive and unfit for human consumption that result in heavy loss to beekeepers. The prevalence of wax moth is high in tropical and sub-tropical region. The wax moth grows and develop quickly in high temperature and cause high damage to apiaries by larval feeding which results in heavy economic loss yearly globally.

Poor management in beekeeping weakens the bee colony, make the colony susceptible to wax moth pest. These pest cause disturbance and nuisance in functioning of the colony. According to IPM, to protect the apiaries from wax moth, the apiaries should be maintained strong by cultural practices.

\section{REFERENCES}

1. Adly, D., \& Marzouk, W. M. (2019). Efficacy of the larval parasitoid, Bracon Hebetor Say. (Hymenoptera: Braconidae) on the greater wax moth larvae, Galleria mellonella (L.) (Lepidoptera: Pyralidae) under laboratory and field conditions. Egyptian Journal of Biological Pest Control, 29(1), 1-7.

2. Javad Nazemi Rafie, Reza Mohamadi \& Hossein Teimory, "Comparison of Two Morphometrics Methods for Discriminating of Honey Bee (Apis mellifera meda Sk.) Populations in Iran", International Journal of Zoology and Research (IJZR),Vol. 4, Issue 3,pp, $61-70$

3. Ambaw, M., Teklehaimannot, T. \& Workye, M. (2020). The prevalence of wax moth and associated risk factors in selected districts of Arsi Zone, Journal of Entomology and Zoology Studies, 8(1), 200-205.

4. Metwally M. Khattab \& El-Hosseny, E. Nowar, "The First Records of the Parasite Zombie Fly (Apocephalus borealis Brues) on Honeybee, Apis mellifera in Egypt ",International Journal of Agricultural Science and Research (IJASR),Vol. 4, Issue 6,pp, $37-42$

5. Bhatnagar, S., Suman, R. K., Sharma, N., \& Sankhla, M. (2020). Infestation of greater wax moth Galleria mellonella in Apis mellifera colonies in Jodhpur (Rajasthan).

6. Wali Khan \& Fouzia Anjum, "Bee Keeping's Impact on Sustainable Livelihoods Development in Bajaur Agency Pakistasn ",International Journal of Applied and Natural Sciences (IJANS), Vol. 5, Issue 6,pp; 39-48

7. Burges, H. D. (1978). Control of wax moths: physical, chemical and biological methods. Bee world, 59(4), 129-138.

8. Desai, A. V., Siddhapara, M. R., Patel, P. K., \& Prajapati, A. P. (2019). Biology of greater wax moth, Galleria mellonella. On artificial diet. J Exp Zool India, 22, 1267-72

9. Ajabush Dafar \& Lelisa Wondimu, "Determinants of Adoption of Improved Beekeeping Technologies in West Shewa and Oromia Special Zone Surrounding Finfine, Oromia Regional State, Ethiopia ",IMPACT: International Journal of Research in Engineering \& Technology, Vol. 9, Issue 1,pp, 11-22

10. Elbehery, H., Abd El-Wahab, T. E., \& Dimetry, N. Z. (2016). Management of the greater wax moth Galleria mellonella with Neem Azal-T/S, in the laboratory and under semi-field conditions. Journal of Apicultural Science, 60(2), 69.

11. Ellis, J. D., Graham, J. R., \& Mortensen, A. (2013). Standard methods for wax moth research. Journal of Apicultural Research, 52(1), 1-17.

12. Goodman, R. (2015). Australian Beekeeping Guide. 
13. Gulati, R., \& Kaushik, H. D. (2004). Enemies of honeybees and their management-a review. Agricultural reviews, 25(3), 189200.

14. Hanumanthaswamy, B. C., \& Rajagopal, D. (2017). Natural enemies of Greater Wax Moth Galleria mellonella Linnaeus in Honey Bee Colonies. International Journal of Current Microbiology and Applied Sciences, 6(8), 3418-3421.

15. Hosamani, V., Hanumantha Swamy, B. C., Kattimani, K. N., \& Kalibavi, C. M. (2017). Studies on biology of greater wax moth (Galleria mellonella L.). Int J Curr Microbiol App Sci, 6, 3811-5.

16. Kapahi, N. \& Lovleen (2019). Honey Bees and its Pest Wax Moth. Journal of Emerging Technologies and Innovative Research, 6(1), 407-412.

17. Kebede, E., Redda, Y. T., Hagos, Y., \& Ababelgu, N. A. (2015). Prevalence of wax moth in modern hive with colonies in kafta humera. Animal and Veterinary Sciences, 3(5), 132.

18. Komala \& Devina, S. (2020). Greater Wax Moth (galleria mellonella L.) - An important insect pest of honeybees. International Journal of Creative Research Thought, 8(11), 1861-1868.

19. Kumar, G., \& Khan, M. S. (2018). Study of the life cycle of greater wax moth (Galleria mellonella) under storage conditions in relation to different weather conditions. J Entomol Zool Stud, 6(3), 444-447.

20. Kwadha, C. A., Ong'amo, G. O., Ndegwa, P. N., Raina, S. K., \& Fombong, A. T. (2017). The biology and control of the greater wax moth, Galleria mellonella. Insects, 8(2), 61.

21. Lalita, Y. K., \& Yadav, S. (2018). Seasonal incidence of Greater wax moth, Galleria mellonella Linnaeus in Apis mellifera colonies in ecological condition of Hisar. Journal of Entomology and Zoology Studies, 6(1), 790-795.

22. Negi, N., Thakur, M., Sharma, H. K., \& Rana, K. (2019). Incidence and management of greater wax moth, Galleria mellonella. Journal of Entomological Research, 43(2), 139-143.

23. Sohail, M., Aqueel, M. A., Ellis, J. D., Afzal, M., \& Raza, A. M. (2017). Seasonal abundance of greater wax moths (Galleria mellonella L.) in hives of western honey bees (Apis mellifera L.) correlates with minimum and maximum ambient temperature. Journal of Apicultural Research, 56(4), 416-420.

24. Swamy, B. H. (2008). Bionomics and biometrics of Greater wax moth Galleria mellonella Linnaeus. Asian Journal of Bio Science, 3(1), 49-51.

25. Tej, M. K., Aruna, R., Mishra, G., \& Srinivasan, M. R. (2017). Beekeeping in India. In Industrial Entomology (pp. 35-66). Springer, Singapore.

26. Tsegaye, A., Wubie, A. J., Eshetu, A. B., \& Lemma, M. (2014). Evaluation of different non-chemical wax moth prevention methods in the backyards of rural beekeepers in the North West dry land areas of Ethiopia. J. Agric. Vet. Sci, 7(3), 29-36.

27. Vijayakumar, K. T., Neethu, T., Shabarishkumar, S., Nayimabanu Taredahalli, M. K., Bhat, N. S., \& Kuberappa, G. C. (2019). Survey, biology and management of greater wax moth, Galleria mellonella L. in Southern Karnataka, India. Journal of Entomology and Zoology Studies, 7(4), 585-592.

28. Wojda, I., Staniec, B., Sułek, M., \& Kordaczuk, J. (2020). The greater wax moth Galleria mellonella: biology and use in immune studies. Pathogens and Disease, 78(9), ftaa057. 


\section{life cycle of wax moth}

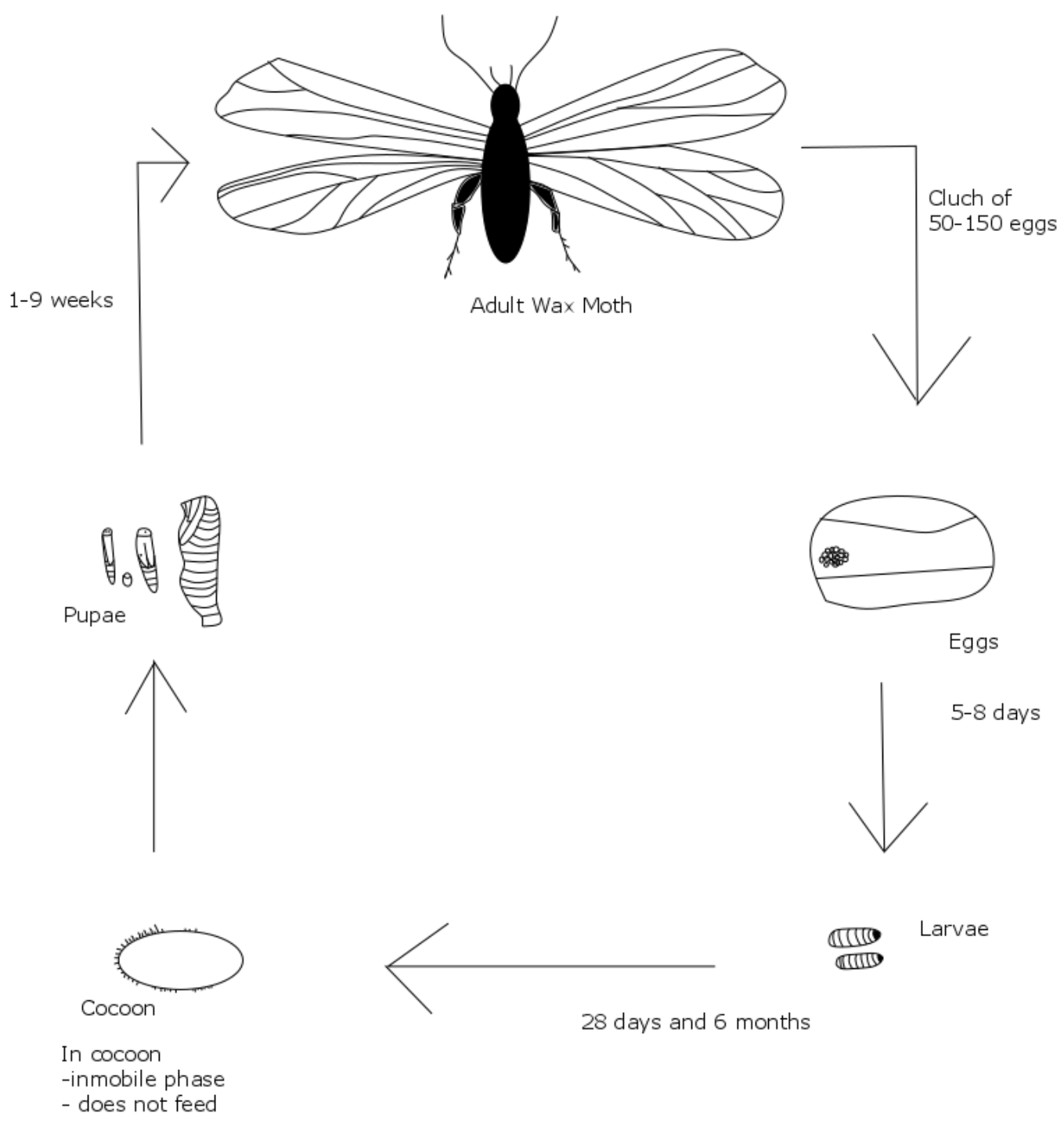

-Duration of life cycle under ideal condition : About 6 weeks to 6 months (Kaushik et al., 2004)

-Egg hatches within 5-8 days (Charles et al., 2017)

- Duration of larval stage under ideal condition is 28 days and 6 months (Charles et al., 2017)

-Duration of pupal stage is 1-9 weeks (Charles et al., 2017)

Figure 1: Life Cycle of Wax Moth. 